\title{
Successive Stages of Mycotic Aortic Arch Aneurysm Development
}

\author{
Walid Ghodbane, MD*, Matthias Kirsch, MD, PhD \\ Department of Cardiothoracic Surgery, Assistance Publique-Hôpitaux de Paris, Hôpital Bichat Claude Bernard, Paris, France
}

\begin{abstract}
An 81-year-old male presented with an abscessed tumor of the cecum and complicated by a mycotic aneurysm of the aortic arch. We present successive stages of mycotic aneurysm development as seen on serial computerized tomography scans.

Copyright $\odot 2015$ Science International Corp.
\end{abstract}

\section{Key Words}

\section{Aortic aneurysm • Computerized tomography}

An 81-year-old male patient with a history of aortic valve replacement presented to our hospital with right iliac fossa pain, chronic constipation, and fever. Hemocultures revealed the presence of anaerobic, Gram-positive bacteria identified as Clostridium septicum [1]. An initial thoraco-abdominal computed tomography (CT) scan demonstrated an abscessed tumor of the cecum with enlarged iliac lymph nodes. The aortic arch was moderately calcified but not dilated (Figure 1A).

After 1 day of triple antibiotic therapy (cefotaxim, gentacillin, and metromidazol), a right hemicolectomy with double enterostomy was performed for an occlusive syndrome. Antibiotics were switched to penicillin plus clavulanic acid as suggested by sensitivity tests.

Two weeks postoperatively, the patient presented with a new septic syndrome, and hemocultures revealed the presence of the same strain of $C$. septicum. A thoraco-abdominal CT scan found no deep abdominal collection, but showed the beginning of dilatation at the distal part of the aortic arch with intra-luminal thrombotic material (Figure 1B).

Fifty days postoperatively, the patient presented with chest pain but no fever. A thoracic CT scan showed a sacciform distal aortic arch aneurysm with intramural air bubbles (Figure $1 C$ and D) suggestive of anaerobic infection [2]. Considering the advanced age of the patient, endovascular temporary exclusion [3] or surgery was declined, and only palliative antibiotics were proposed (penicillin + clavulanic acid in addition to metromidazol). The patient subsequently died of aortic arch rupture.

\section{Conflict of Interest}

The authors have no conflicts of interest relevant to this publication.

\section{Comment on this Article or Ask a Question}

* Corresponding Author:

Walid Ghodbane, MD

Department of Cardiothoracic Surgery

Bichat-Claude-Bernard Hospital

75877 Paris Cedex 18, Paris, France

Phone: +33 1402589 46; Fax: +33 1402586 23; E-Mail: ghodbane.walid@gmail.com 

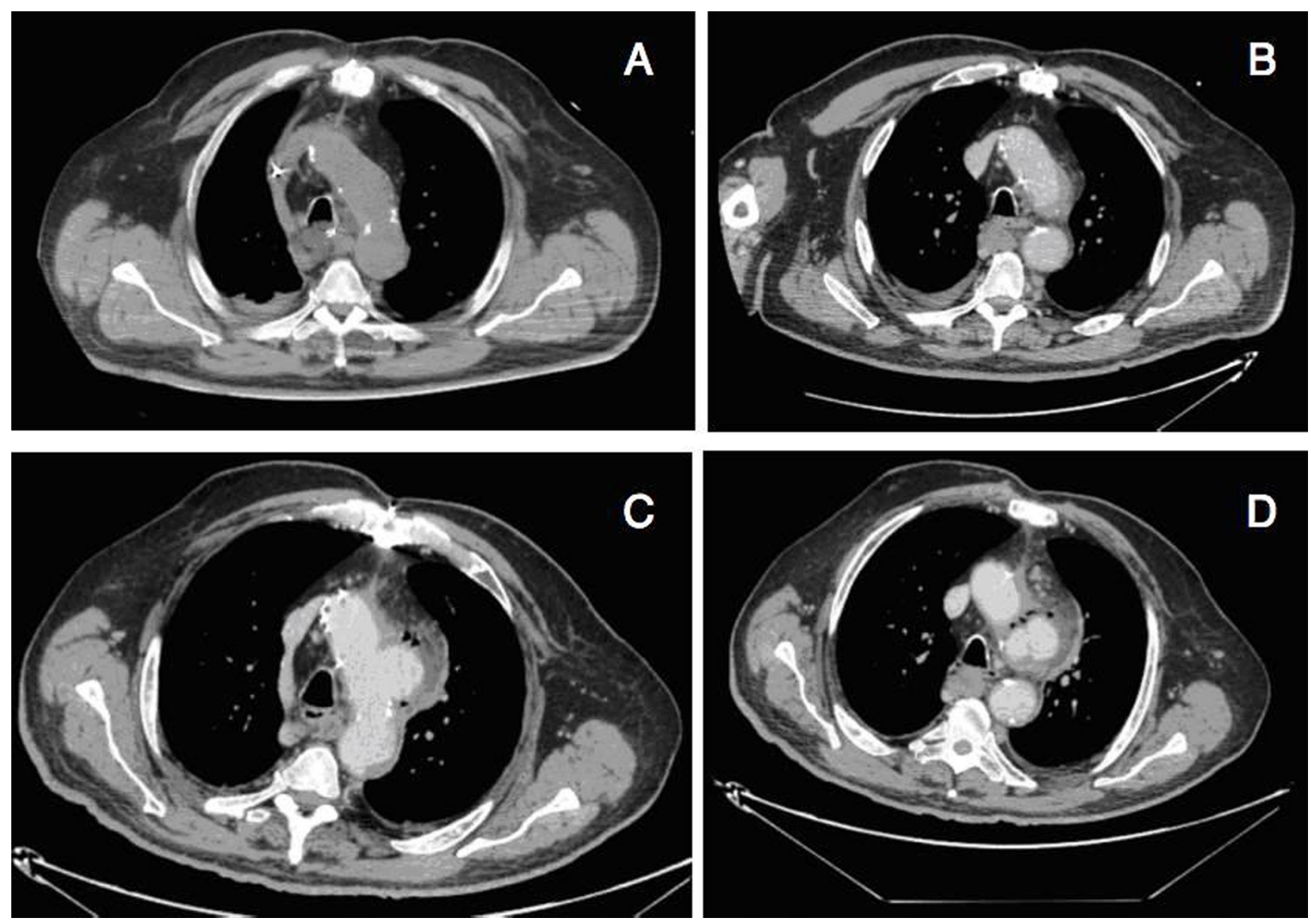

Figure 1. Thoracic computed tomographic scan. Axial images (Panel A and Panel C same level; Panel B and Panel D same level). Panel A. Day 0 , showing a moderately calcified aortic arch. Panel B. Day 14, showing the beginning of dilatation of the distal part of the aortic arch with intraluminal hypo-dense material suggestive of thrombus. (Panel C and Panel D) Day 50, showing a sacciform distal aortic arch aneurysm with air within the aortic wall suggestive of anaerobic infection.

\section{References}

1. Munshi IA, Rhee SW, Pane T, Granowitz E. Clostridium septicum mycotic aortic aneurysm. Am J Surg. 2002;184:54-55. DOI: 10.1016/S0002-9610(02)00883-8

2. Yang $C Y$, Liu $\mathrm{KL}$, Lee CW, Tsang YM, Chen SJ. Mycotic aortic aneurysm: Presenting initially as an aortic intramural air pocket.
AJR Am J Roentgenol. 2005; 85:463-465. DOI: 10.2214/ajr.185.2.01850463

3. Kan CD, Lee HL, Yang YJ. Outcome after endovascular stent graft treatment for mycotic aortic aneurysm: A systematic review. J Vasc Surg. 2007;46:906-912. DOI: 10.1016/j.jvs.2007.07.025
Cite this article as: Ghodbane W, Kirsch M. Successive Stages of Mycotic Aortic Arch Aneurysm Development. AORTA (Stamford). 2015;3(6):199-200. DOI: http://dx.doi.org/10.12945/j.aorta. 2015.14.055 